\title{
Fracture Response of Reinforced Concrete Deep Beams Finite Element Investigation of Strength and Beam Size
}

\author{
Guillermo A. Riveros ${ }^{1}$, Vellore Gopalaratnam ${ }^{2}$ \\ ${ }^{1}$ Information Technology Laboratory, US Army Engineer Research and Development Center, Vicksburg, MS, USA \\ ${ }^{2}$ Department of Civil and Environmental Engineering, University of Missouri-Columbia, Columbia, MO, USA \\ Email: Guillermo.A.Riveros@us.army.mil
}

Received January 8, 2013; revised February 8, 2013; accepted February 15, 2013

Copyright (C) 2013 Guillermo A. Riveros, Vellore Gopalaratnam. This is an open access article distributed under the Creative Commons Attribution License, which permits unrestricted use, distribution, and reproduction in any medium, provided the original work is properly cited.

\begin{abstract}
This article presents a finite element analysis of reinforced concrete deep beams using nonlinear fracture mechanics. The article describes the development of a numerical model that includes several nonlinear processes such as compression and tension softening of concrete, bond slip between concrete and reinforcement, and the yielding of the longitudinal steel reinforcement. The development also incorporates the Delaunay refinement algorithm to create a triangular topology that is then transformed into a quadrilateral mesh by the quad-morphing algorithm. These two techniques allow automatic remeshing using the discrete crack approach. Nonlinear fracture mechanics is incorporated using the fictitious crack model and the principal tensile strength for crack initiation and propagation. The model has been successful in reproducing the load deflections, cracking patterns and size effects observed in experiments of normal and high-strength concrete deep beams with and without stirrup reinforcement.
\end{abstract}

Keywords: Automatic Remeshing; Bond Slip; Concrete; Discrete Crack; Finite Element; Fracture Mechanics; Size Effects; Tensile Softening

\section{Introduction}

Reinforced concrete (RC) deep beams have useful applications in tall buildings, offshore structures, foundations, and military structures. A significant number of failures in $\mathrm{RC}$ structures initiate in tension regions caused by areas of high-stress concentrations or preexisting cracks. Stable growth of these tensile cracks, until peak loads, is associated with the development of large zones of fracture (fracture process zone (FPZ)). The growth of the FPZ, until peak load is reached, introduces the effect of structural size on the failure loads. Hence, if one was to design structures based on equations that were developed based on strength analysis, as in current American Concrete Institute (ACI) code [1], the margin of safety provided would depend upon the size of the structure. The margin of safety will be higher for smaller structures than for larger ones. It is also conceivable that this approach would lead to unconservative designs for some very large structures, e.g., deep slabs for underground storage tanks.

Early attempts [2] to analyze failure in concrete structures caused by crack growth were not successful, even though it was obvious that a fracture mechanics approach would be realistic to model brittle crack propagation type failures. The lack of success in the early attempts to analyze crack propagation failures was due to the use of linear elastic fracture mechanics (LEFM). LEFM assumes that the fracture process is small and can be replaced, and that the rest of the member volume remains elastic; however, research in the last four decades has resulted in modifications to LEFM to account for the distributed nature of pre-peak micro-cracking and the presence of a large FPZ in concrete [3-6]. These modifications have produced better results in the application of fracture mechanics concepts to brittle failure in reinforced concrete. Theories that allow tensile softening and FPZ of relatively large sizes are classified as nonlinear fracture mechanics models.

A considerable effort has been committed to develop numerical models to simulate the fracture behavior of materials exhibiting tensile softening and FPZ, such as mortar, concrete, rock, or bricks used in civil engineering structures $[4,7]$. Two numerical methods to simulate fracture are available; the smeared crack approach and dis- 
crete crack approach. In the smeared crack approach, introduced by [8], the crack is replaced by a continuous medium with altered mechanical properties. Because the crack is established through stress computations at integration points, a significant number of cracks with small openings are imagined to be continually distributed over the finite element. The constitutive laws, defined by stressstrain relations, are nonlinear and may exhibit strain softening. Strain localization instabilities and spurious mesh sensitivity of finite element calculations are likely, when strain softening is modeled numerically. These difficulties can be overcome by adopting appropriate mathematical techniques [6].

In the discrete crack approach, the crack is formulated as a geometrical change that requires remeshing each time a crack is initiated or propagated. The computational demand, as a result, has been one of the biggest drawbacks of the method; however, this article shows the development of multicrack initiation and propagation procedures that enhance the method and make it less cumbersome. The cohesive crack model, developed by [2] and discussed in [9], has been shown to be effective for modeling the nonlinear fracture behavior of RC (fracture process of quasi-brittle materials).

Several numerical models have been developed to study the behavior of brittle failure (shear) of reinforced concrete beams [10-13]. Because these models differ in material models, element formulations, and solution procedures, a specific approach will be more suited for specific structures and/or loading situations and less suited to others [13]; however, nonlinear fracture mechanics models are capable of analyzing the complete behavior of reinforced concrete beams of any size and loading geometry.

This article presents a nonlinear fracture mechanics finite element code that incorporates nonlinear fracture mechanics analysis on reinforced concrete beams. The system uses the discrete crack approach with the fictitious crack model (FCM) $[2,9,14,15]$ to represent the tensile softening of concrete; the Shah-Fafitis-Arnold model [16] to characterize compression softening; a nonlinear bond-slip constitutive model to account for bond-slip degradation observed when cracks cross the tensile reinforcement $[12,17]$ and an elastic, perfectly plastic constitutive model to represent the yielding of the tensile reinforcement.

A multicrack initiation and propagation routine incorporating the Delaunay refinement algorithm [18] to create a triangular topology necessary to obtain a highquality mesh when multiple cracks are generated in $\mathrm{RC}$ beams that are transformed into a quadrilateral mesh by the quad-morphing algorithm [19] has also been developed.

The primary motivation for this investigation is to study brittle shear failures in reinforced concrete beams from a nonlinear fracture mechanics and finite element point of view and to study the implications for shear design practices. A secondary motivation is to study brittleness in a more general context that includes structural (size and loading geometry) and material contributions to brittleness. The model has been successful in reproducing the load deflections, cracking patterns and size effects observed in experiments of normal and high-strength concrete deep beams with and without stirrup reinforcement [20] with shear-span-to-depth ratios $a / d$ of 1.5 and 2.5 .

\section{Experimental Evaluation}

[21] conducted systematic experiments to characterize the structural and material response of over 150 reinforced concrete deep beams with and without shear reinforcement. Four beam sizes and three different concrete mixes were used. The effective depths $d$ used were 50, 100,200 , and $800 \mathrm{~mm}(2,4,8$, and 32 in.). Shear-spanto-depth ratios a/d of 1.5 and 2.5 were also used to characterize different failure modes. Results from the two larger beams with and without shear reinforcement were used in this numerical study for comparisons (Figure 1 and Tables 1 and 2).

Compressive response of concrete was obtained using specimens cored (75-mm (3 in.) diameter, 150-mm (6 in.) length) and tested under specimen displacement controlled conditions to obtain the complete (including post-peak softening) stress strain response [22]. Mode I fracture parameters were obtained testing notched beams on a

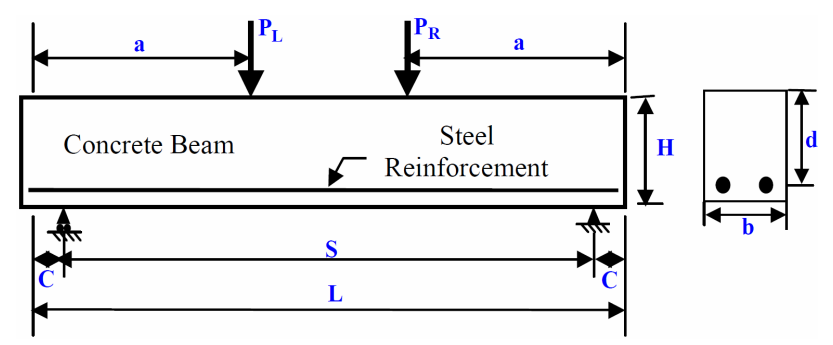

(a)

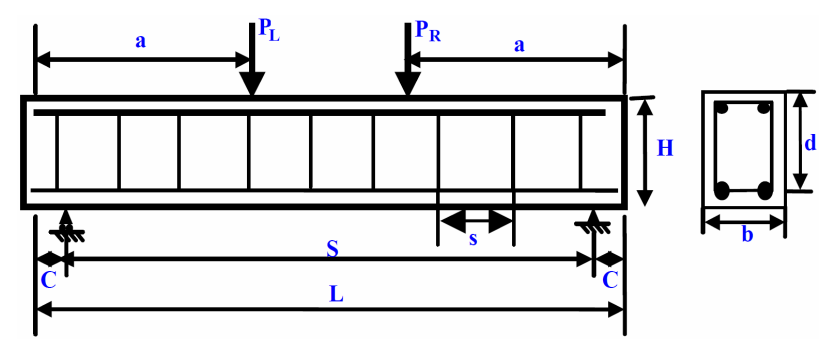

(b)

Figure 1. Details of beam geometry and loading configuration for beam (a) without stirrup reinforcement and (b) with stirrup reinforcement. 
Table 1. Dimensional details of the reinforced concrete beams (dimensions are in $\mathbf{m m}$ (inches)).

\begin{tabular}{ccc}
\hline & Size A & Size B \\
\hline $\boldsymbol{L}$ & 5486.4 & 1422.4 \\
& $(216.0)$ & $(56.0)$ \\
$\boldsymbol{S}$ & 4876.8 & 1219.2 \\
& $(192.0)$ & $(48.0)$ \\
$\boldsymbol{H}$ & 914.4 & 241.3 \\
& $(36.0)$ & $(9.5)$ \\
$\boldsymbol{b}$ & 152.4 & 152.4 \\
& $(6.0)$ & $(6.0)$ \\
$\boldsymbol{d}$ & 812.8 & 203.2 \\
& $(32.0)$ & $(8.0)$ \\
& $1219.2[1.5]$ & $304.8[1.5]$ \\
$\boldsymbol{a}[\boldsymbol{a} / \boldsymbol{d}]$ & $(48.0)$ & $(12.0)$ \\
& $2032.0[2.5]$ & $508.0[2.5]$ \\
& $(80.0)$ & $(20.0)$ \\
\hline
\end{tabular}

Table 2. Material properties from tests.

\begin{tabular}{|c|c|c|c|c|}
\hline \multirow{3}{*}{ Property } & \multicolumn{4}{|c|}{ Mix } \\
\hline & \multicolumn{2}{|c|}{$\mathrm{NSC}$} & \multicolumn{2}{|c|}{ HSC } \\
\hline & 28 Days & Test & 28 Days & Test \\
\hline $\begin{array}{c}f_{c}^{\prime}, \mathrm{MPa} \\
\quad(\mathrm{psi})\end{array}$ & $\begin{array}{c}32.2 \\
(4668)\end{array}$ & $\begin{array}{c}43.0 \\
(6238)\end{array}$ & - & $\begin{array}{c}72.9 \\
(10,570)\end{array}$ \\
\hline$\underset{(\mathrm{psi})}{E, \mathrm{MPa}}$ & $\begin{array}{c}19,289 \\
(2,797,650)\end{array}$ & $\begin{array}{c}29,320 \\
(4,252,520)\end{array}$ & - & $\begin{array}{c}31,354 \\
(4,547,560)\end{array}$ \\
\hline $\begin{array}{c}f_{t}, \mathrm{MPa} \\
(\mathrm{psi})\end{array}$ & & & & \\
\hline $\begin{array}{c}G_{f}, \mathrm{~N} / \mathrm{mm} \\
(\mathrm{lb} / \mathrm{in} .)\end{array}$ & $\begin{array}{r}0.10 \\
(0.57\end{array}$ & $\begin{array}{l}028 \\
267)\end{array}$ & & $\begin{array}{l}100 \\
967)\end{array}$ \\
\hline
\end{tabular}

three-point loading configuration. Material properties and fracture energy for normal-strength concrete (NSC) and high-strength concrete (HSC) are presented in Table 2.

For beam sizes A and B, [20] used two ram displacements controlled by a dual ramp command function. For size A beams he used an initial load ratio of $25 \mathrm{~mm}(1$ in.)/hour for the first half hour and a ratio of $76 \mathrm{~mm} \mathrm{(3.0}$ in.)/hour thereafter. For size B beams he used an initial load ratio of $7.1 \mathrm{~mm}(0.28 \mathrm{in}$.)/hour and a ratio of 25.0 $\mathrm{mm}$ (1.0 in.)/hour until failure. Load displacement behaviors obtained in the experiments were then used in the numerical model to determine the force boundary conditions needed to predict a similar response.

\section{Fracture Mechanics Analysis of Reinforced Concrete Beams (FMARCB)}

A finite element system, Fracture Mechanics Analysis of Reinforced Concrete Beams (FMARCB) [23], has been developed to perform nonlinear fracture mechanics analysis on reinforced concrete beams. The system consists of a graphic input interface, analysis routines using finite element techniques, and graphic output interface. FMA$\mathrm{RCB}$ is a two-dimensional finite element program with triangular ( 3 and 6 nodes), isoparametric (4 and 8 nodes), bar (truss), and interface elements (bond-link). The system uses the discrete crack approach with the FCM $[2,9,14,15]$ to represent the tensile concrete softening; the Shah-Fafitis-Arnold model [16] to characterize the compression softening; a nonlinear bond-slip constitutive model for the bond-slip phenomenon, which is degraded when cracks cross the tensile reinforcement $[12,17]$ and an elastic perfectly plastic constitutive model to represent the yielding of the tensile reinforcement.

The analysis begins with the definition of the finite element model of the continuum in the elastic state. Once the elastic analysis of the system is completed for the first load step and the principal stresses are extrapolated at the nodes, cracking criteria based on the principal tensile stresses are verified. If the principal tensile stress exceeds the tensile strength, a fictitious crack is incorporated at the location and automatic remeshing is undertaken. Once the system has cracked, the nonlinear solver is activated. If new cracks and extensions are required after the nonlinear problem satisfies equilibrium for an unbalanced tolerance, the system is remeshed with new cracks and the existing crack extensions. It is then calibrated again for the same load step until no new cracks or extensions are required. This iterative process is repeated for each load step.

FMARCB incorporates the Delaunay refinement algorithm [8] to create a triangular topology that then is transformed into a quadrilateral mesh by the quad-morphing algorithm [19]. The Delaunay refinement mesh generation algorithm constructs meshes of triangular elements. The algorithm operates by imposing a Delaunay or constrained Delaunay triangulation that is refined by inserting additional vertices until the mesh meets constraints on element quality and size. These algorithms simultaneously offer theoretical bounds on element quality, edge lengths, and spatial grading of element sizes. They also possess the ability to triangulate general straight-line domains.

Quad-morphing [19] is a technique used for generating quadrilaterals from an existing triangle mesh. Beginning with an initial triangulation, triangles are systematically transformed and combined. Quad-morphing can be categorized as an unstructured, indirect method that utilizes an advancing front algorithm to form an all-quad mesh. As an indirect method it is able to take advantage of local topology information from the initial triangulation. Unlike other indirect methods it is able to generate boundary- 
sensitive rows of elements, with few irregular nodes.

\section{Nonlinear Fracture Mechanics Using the Fictitious Crack Model}

The FCM assumes that there is an inelastic zone (FPZ) ahead of the crack tip $[2,14]$. Along the FPZ, the stress carrying capacity decreases as a function of the crack opening displacement (COD). The FPZ is characterized by a normal stress versus COD response (Figure 2), which is considered a material property. This model adopts the tensile strength criterion for crack initiation and subsequent growth. It also assumes that a stress-free crack occurs when the COD is larger than the critical $\operatorname{COD} w_{c}$.

\section{Material Properties Characterization}

Tension softening curve. FMARCB has the capability to use either a linear or bilinear softening curve (Figure 2). The fictitious crack model is incorporated into the finite element analysis by employing interface elements. For a linear softening curve, the critical COD value $w_{c}$ is

$$
w_{c}=\frac{2 G_{f}}{f_{t}}
$$

where, $G_{f}$ is the fracture energy, $f_{t}$ is the tensile strength, and $w_{c}$ is the COD, when the tensile capacity is reduced to zero.

Figure 2 also shows the bilinear softening curve proposed by [24], where $w_{c}$ is

$$
w_{c}=3.6 \frac{G_{f}}{f_{t}}
$$

and $w_{1}$ is

$$
w_{1}=0.8 \frac{G_{f}}{f_{t}}
$$

where $w_{1}$ is the COD at the kink of the bilinear curve, $w_{c}$ is the COD when the tensile carrying capacity is completely lost, and the stress at the kink is $1 / 3 f_{t}$. In the FCM the interface element is a nonlinear function of the

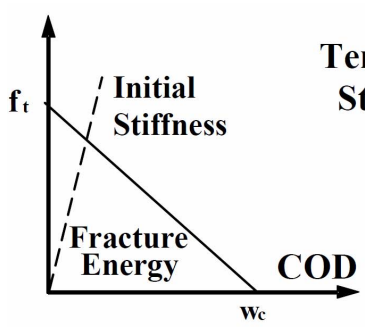

(a)

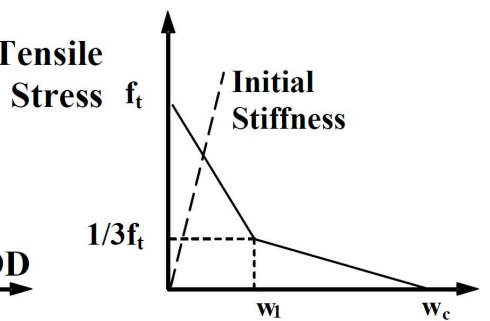

(b)
Figure 2. FMARCB tension softening models: (a) Linear; (b) Nonlinear.
COD as shown in Figure 2. When interface elements are used to model the FPZ, care must be taken to avoid divergent numerical behavior. Figure 2 shows that when the COD is small, the stiffness of the interface element is large, which requires a small load step for convergence [25]. A finite initial stiffness has to be used as shown in Figure 2. An initial stiffness corresponding to $w_{c} / 20$ to $w_{c} / 30$ has been used by [25] with success.

Compression softening. The compression softening model used in this work is the one proposed by [16]. The model describes well, the stress-strain relation for confined and unconfined concrete. The ascending part of the model is described by

$$
f=f_{0}\left[1-\left(1-\frac{\varepsilon}{\varepsilon_{0}}\right)^{A}\right]
$$

and the descending part as

$$
f=f_{0} \exp \left(-k\left(\varepsilon-\varepsilon_{0}\right)^{1.15}\right)
$$

where $f$ is the stress corresponding to the predefined strain $\varepsilon$, and the peak stress $f_{0}$ and peak strain $\varepsilon_{0}$ for laterally confined concrete are defined as

$$
\begin{gathered}
f_{0}=f_{c}^{\prime}+\left(1.15+\frac{21000}{f_{c}^{\prime}}\right) f_{r}(\mathrm{KPa}) \\
f_{0}=f_{c}^{\prime}+\left(1.15+\frac{3048}{f_{c}^{\prime}}\right) f_{r}(\mathrm{psi}) \\
\varepsilon_{0}=1.491 E^{8} f_{c}^{\prime}+0.0296 \frac{f_{r}}{f_{c}^{\prime}}+0.00195(\mathrm{KPa}) \\
\varepsilon_{0}=1.027 E^{-7} f_{c}^{\prime}+0.0296 \frac{f_{r}}{f_{c}^{\prime}}+0.00195(\mathrm{psi})
\end{gathered}
$$

where $f_{c}^{\prime}$ is the compressive strength for unconfined concrete and $f_{r}$ is the confinement pressure.

The confinement pressure $f_{r}$ is then defined as

$$
f_{r}=\frac{2 A_{v} f_{y}}{s d_{c}}
$$

where $A_{v}$ is the area of the lateral reinforcement, $f_{y}$ is the yield strength of the stirrups, $s$ is the spacing between stirrups, and $d_{c}$ is the diameter of the concrete core.

Parameters $A$ and $k$ are constants that were statistically evaluated from experimental data of unconfined and confined concrete subjected to monotonically increasing loading [16] and are defined as

$$
\begin{gathered}
A=\frac{E_{c} \varepsilon_{0}}{f_{0}} \\
k=0.025 f_{c}^{\prime} \exp \left(-0.00145 f_{r}\right)(\mathrm{KPa})
\end{gathered}
$$




$$
k=0.17 f_{c}^{\prime} \exp \left(-0.01 f_{r}\right)(\mathrm{psi})
$$

where $E_{c}$ is the secant modulus of elasticity.

Bond-slip curve. The bond between concrete and reinforcement is one of the most important factors influencing the capacity of a reinforced concrete beam. Bond is the load-carrying mechanism between concrete and reinforcement in the longitudinal direction of the reinforcing bar. In regions of high stress at the contact interface, the bond stresses are related to relative displacements, usually called bond-slip, which are caused by different average strains in the concrete and reinforcement [26].

The bond stress-slip relationship depends on a considerable number of influencing factors including bar roughness (relative rib area), concrete strength, position and orientation of the bar during casting, state of stress, boundary conditions, and concrete cover [12].

Figure 3 shows the bond-slip curve used in FMARCB; here the ascending part of the curve refers to the stage in which the ribs penetrate into the mortar matrix, characterized by local crushing and microcracking. The descending part that starts at the maximum bonding strength $\tau_{\max }$ of the curve refers to the reduction of bond resistance from the occurrence of splitting cracks, transverse to the bars. The horizontal part characterizes a residual bond capacity $\tau_{\min }$, which can be attributed to frictional slip based load transfer.

The following considerations apply to the generation of bond stresses. Reinforcement and concrete have the same strain $\left(\varepsilon_{s}=\varepsilon_{c}\right)$ in those areas of the structure under compression and in the uncracked parts of the structure under tension. Bond stresses are generated between the concrete and the reinforcing steel by the relative displacement $s_{s}=u_{s}-u_{c}$ where $u_{s}$ is the displacement of the steel and $u_{c}$ is the concrete displacement. The magnitude of these bond stresses depends predominantly on the steel stresses, the slip $s$, the concrete compressive strength $f_{c}^{\prime}$, and the position of the reinforcement during placing (top cast or bottom cast). Tension stiffening, a term needed to describe the contribution of the concrete between cracks

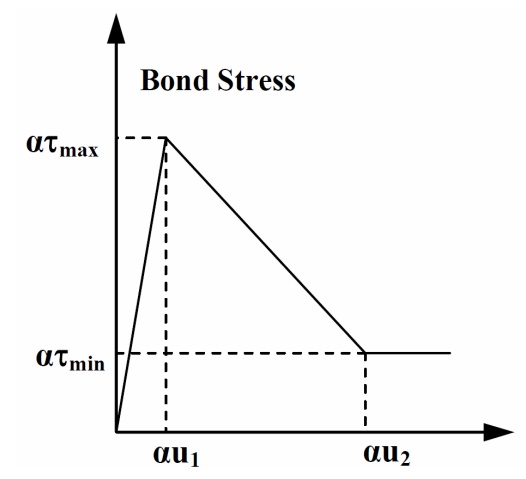

Figure 3. Bond-slip model. to the stiffness of the cracked concrete beam, is also effective as a result of the interface bond between steel and concrete.

Degradation of bond-slip caused by cracking. Bond behavior has the same important influence on the response to applied loads of reinforced concrete beams as the properties of reinforcement and concrete. Bond stiffness and maximum bond stresses deteriorate near the cracks in proportion to the distance to the crack and the bar diameter [17]. [12,17] have reported that bond degradation occurs in the vicinity of flexure cracks. To account for this degradation of bonding, they recommend the calculation of the reduction factor $\alpha$, which is then applied to the bond stresses of the original bond-slip function. The reduction factor proposed by [12] is determined as follows:

$$
a=0.20 \frac{x}{d_{s}} \leq 1
$$

where $x$ is the distance from the crack-rebar intersection center line to the desirable location, and $d_{s}$ is the bar diameter.

\section{Interface Element}

To model tensile softening in concrete and bond-slip for the steel-concrete interaction, the bond-link element [27] was implemented in FMARCB. These elements can calculate the stresses generated between any two surfaces (steel and concrete (bond-slip) or concrete to concrete (softening)) as a function of the relative displacements between the surfaces. This type of element relies on normal and shear stiffness to simulate the strength between the two surfaces. The constitutive models used for the concrete tensile softening and the bond-slip are shown in Figures 2 and 3. As seen in the constitutive models, the bond-link element requires a nonlinear solver in contrast to the linear behavior first proposed by [27].

\section{Model Validation}

Numerical analyses were conducted on two sizes of geometrically proportionate reinforced concrete beams [20] with normal and high compressive strengths with and without shear reinforcement. The beams were analyzed with $a / d$ ratios of 2.5 and 1.5. Figure 1 and Table $\mathbf{1}$ show the beam size and loading configurations, while Table 3 lists the parameters used in the numerical computations for beams with and without shear reinforcement. Results from numerical models were then compared to experimental results [20]. Further analyses were also conducted on the larger size beams with shear reinforcement. Results of load displacement, cracking patterns, size effects, and concrete strength are discussed in the following section. 
Table 3. Numerical model parameters for beams without shear reinforcement.

\begin{tabular}{|c|c|c|c|c|c|c|}
\hline \multirow[b]{2}{*}{ Parameter } & \multicolumn{6}{|c|}{ Beam } \\
\hline & $\begin{array}{l}\text { ANW21 } \\
\text { and } \\
\text { ANW11 }\end{array}$ & $\begin{array}{l}\text { AHW21 } \\
\text { and } \\
\text { AHW11 }\end{array}$ & $\begin{array}{l}\text { BNW21 } \\
\text { and } \\
\text { BNW11 }\end{array}$ & $\begin{array}{l}\text { BHW21 } \\
\text { and } \\
\text { BHW11 }\end{array}$ & $\begin{array}{l}\text { ANS22 } \\
\text { and } \\
\text { ANS11 }\end{array}$ & $\begin{array}{l}\text { AHS22 } \\
\text { and } \\
\text { AHS11 }\end{array}$ \\
\hline $\begin{array}{c}E, \mathrm{GPa} \\
(\mathrm{psi})\end{array}$ & $\begin{array}{c}29 \\
(4.25 \mathrm{E} 6)\end{array}$ & $\begin{array}{c}31 \\
(4.50 \mathrm{E} 6)\end{array}$ & $\begin{array}{c}29 \\
(4.25 \mathrm{E} 6)\end{array}$ & $\begin{array}{c}31 \\
(4.50 \mathrm{E} 6)\end{array}$ & $\begin{array}{c}29 \\
(4.25 \mathrm{E} 6)\end{array}$ & $\begin{array}{c}31 \\
(4.50 \mathrm{E} 6)\end{array}$ \\
\hline $\begin{array}{c}f_{c}^{\prime}, \mathrm{MPa} \\
(\mathrm{psi})\end{array}$ & $\begin{array}{c}44.8 \\
(6500)\end{array}$ & $\begin{array}{c}68.9 \\
(10,000)\end{array}$ & $\begin{array}{c}44.8 \\
(6500)\end{array}$ & $\begin{array}{c}68.9 \\
(10,000)\end{array}$ & $\begin{array}{c}44.8 \\
(6500)\end{array}$ & $\begin{array}{c}68.9 \\
(10,000)\end{array}$ \\
\hline$v$ & 0.18 & 0.18 & 0.18 & 0.18 & 0.18 & 0.18 \\
\hline $\begin{array}{l}f_{t}, \mathrm{MPa} \\
\quad(\mathrm{psi})\end{array}$ & $\begin{array}{c}4.1 \\
(600)\end{array}$ & $\begin{array}{c}4.3 \\
(625)\end{array}$ & $\begin{array}{c}4.1 \\
(600)\end{array}$ & $\begin{array}{c}4.3 \\
(625)\end{array}$ & $\begin{array}{c}4.1 \\
(600)\end{array}$ & $\begin{array}{c}4.3 \\
(625)\end{array}$ \\
\hline$A_{s}$ & $2 \# 8$ & $4 \# 8$ & $2 \# 4$ & $4 \# 4$ & $2 \# 8$ & $4 \# 8$ \\
\hline$A^{\prime}$ s & & & & & $2 \# 4$ & $2 \# 4$ \\
\hline $\begin{array}{c}E_{s}, \mathrm{GPa} \\
\quad(\mathrm{psi})\end{array}$ & $\begin{array}{c}209 \\
(30 \mathrm{E} 6)\end{array}$ & $\begin{array}{c}209 \\
(30 \mathrm{E} 6)\end{array}$ & $\begin{array}{c}209 \\
(30 \mathrm{E} 6)\end{array}$ & $\begin{array}{c}209 \\
(30 \mathrm{E} 6)\end{array}$ & $\begin{array}{c}209 \\
(30 \mathrm{E} 6)\end{array}$ & $\begin{array}{c}209 \\
(30 \mathrm{E} 6)\end{array}$ \\
\hline $\begin{array}{c}f_{y}, \mathrm{MPa} \\
(\mathrm{psi})\end{array}$ & $\begin{array}{c}462 \\
(67,000)\end{array}$ & $\begin{array}{c}462 \\
(67,000)\end{array}$ & $\begin{array}{c}441 \\
(64,000)\end{array}$ & $\begin{array}{c}441 \\
(64,000)\end{array}$ & $\begin{array}{c}462 \\
(67,000)\end{array}$ & $\begin{array}{c}462 \\
(67,000)\end{array}$ \\
\hline $\begin{array}{l}w_{c}, \mathrm{~mm} \\
\text { (in.) }\end{array}$ & $\begin{array}{c}0.0484 \\
(0.0019)\end{array}$ & $\begin{array}{c}0.0422 \\
(0.0016)\end{array}$ & $\begin{array}{c}0.0484 \\
(0.0019)\end{array}$ & $\begin{array}{c}0.0422 \\
(0.0016)\end{array}$ & $\begin{array}{c}0.0484 \\
(0.0019)\end{array}$ & $\begin{array}{c}0.0422 \\
(0.0016)\end{array}$ \\
\hline $\begin{array}{l}\tau_{\max }, \mathrm{MPa} \\
\quad(\mathrm{psi})\end{array}$ & $\begin{array}{c}5.5 \\
(800)\end{array}$ & $\begin{array}{c}5.5 \\
(800)\end{array}$ & $\begin{array}{c}5.5 \\
(800)\end{array}$ & $\begin{array}{c}5.5 \\
(800)\end{array}$ & $\begin{array}{c}5.5 \\
(800)\end{array}$ & $\begin{array}{c}5.5 \\
(800)\end{array}$ \\
\hline $\begin{array}{l}u_{1}, \mathrm{~mm} \\
\text { (in.) }\end{array}$ & $\begin{array}{c}0.0127 \\
(0.0005)\end{array}$ & $\begin{array}{c}0.0127 \\
(0.0005)\end{array}$ & $\begin{array}{c}0.0127 \\
(0.0005)\end{array}$ & $\begin{array}{c}0.0127 \\
(0.0005)\end{array}$ & $\begin{array}{c}0.0127 \\
(0.0005)\end{array}$ & $\begin{array}{c}0.0127 \\
(0.0005)\end{array}$ \\
\hline $\begin{array}{c}u_{2}, \mathrm{~mm} \\
\text { (in.) }\end{array}$ & $\begin{array}{c}1.02 \\
(0.04)\end{array}$ & $\begin{array}{c}1.02 \\
(0.04)\end{array}$ & $\begin{array}{l}1.02 \\
(0.04)\end{array}$ & $\begin{array}{c}1.02 \\
(0.04)\end{array}$ & $\begin{array}{c}1.02 \\
(0.04)\end{array}$ & $\begin{array}{c}1.02 \\
(0.04)\end{array}$ \\
\hline
\end{tabular}

\section{Numerical Solution without Shear Reinforcement}

Typical load deflection response. Load deformation responses are discussed for sizes $\mathrm{A}$ and $\mathrm{B}$. The overall load deformation behavior, observed in size A beams, is representative of the other sizes. Aspects of the response, unique to size $\mathrm{B}$ members, are also discussed. In the analysis presented herein, the results shown included the members' self-weight.

Results from the numerical analysis of an NSC beam without lateral reinforcement (Beam ANW21) and a shearspan-to-depth ratio of 2.5 , indicated a diagonal tension failure after yielding of the longitudinal steel reinforcement. This type of failure was driven by an unstable growth of a flexure shear crack (Figure 4).

Typically, the load deflection response is linear until the first flexural crack appears in the tension face (Point 1 in Figure 5). Flexural cracks in the inner span of the beam grow in number and size with continued loading. Further loading produces diagonal cracks at the midheight of the beam. This stage in the load deflection response is denoted as Point 2 in Figure 5. At this load level, debonding of the steel begins; with additional load, the bond capacity deteriorates, reflecting added nonlinear behavior that causes deflections to increase more rapidly. Also, some flexural cracks that develop in the shear span curve toward midspan at beam midheight and continue to grow. This is shown as Point 3 in Figure 5. Longitudinal steel yielding initiates at Point 4 in Figure 5. Ultimate failure occurs after reinforcement reaches failure.

Figure 6 presents results from the test of an HSC beam without lateral reinforcement (Beam AHW22). A shear-span-to-depth ratio of 2.5 was used in the numerical model. The beam failed from diagonal tension failure. Once again, the failure was driven by the unstable crack growth of a flexure shear crack combined with debonding of the longitudinal reinforcement; however, no yielding of the longitudinal reinforcement was observed prior to failure.

Initial stiffness differences result from the higher modulus for the HSC matrix and the larger steel content used in the HSC beam. The increased load and deflection capacity between diagonal cracking and ultimate capacity depends upon the geometry and material characteristics. For the beam geometry and material properties used in this investigation, ultimate capacity in all the modes of failure and for all beam sizes was distinct from diagonal cracking.

In the case of NSC and HSC beams without stirrup reinforcement analyzed at an a/d ratio of 1.5 (Beams ANW11 and AHW11 in Table 3), multiple diagonal tension cracks in each shear span (as shown in Figure 7, to be discussed later) were observed at incipient failure. A 


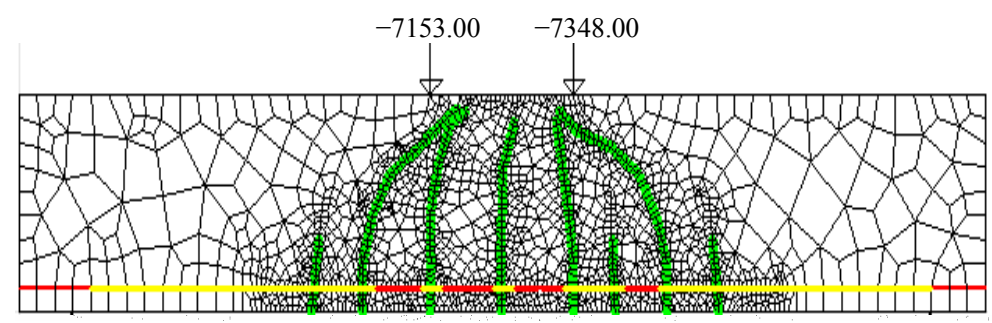

(a)

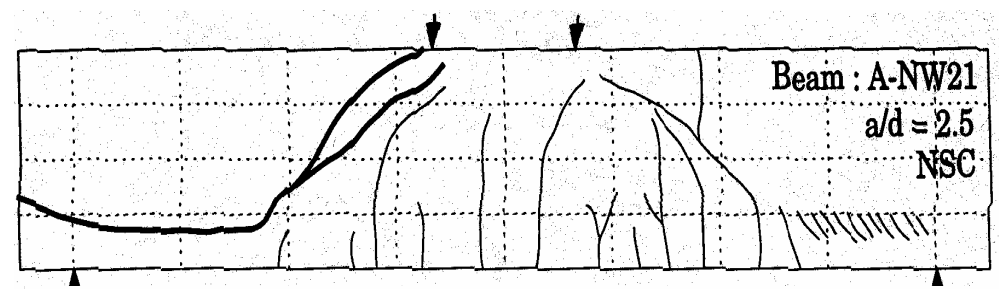

(b)

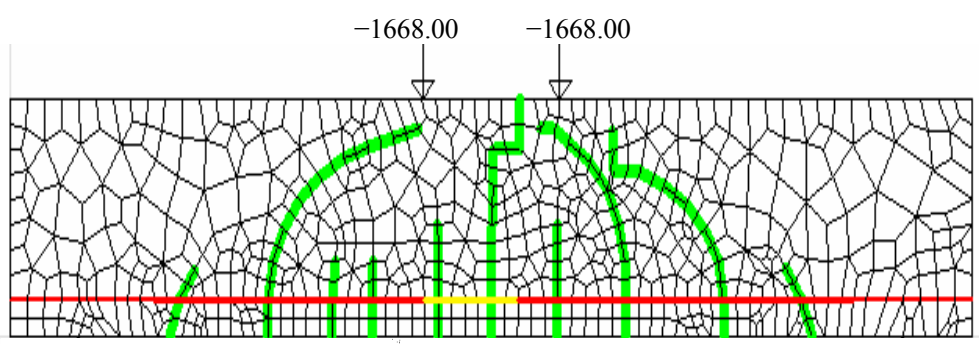

(c)

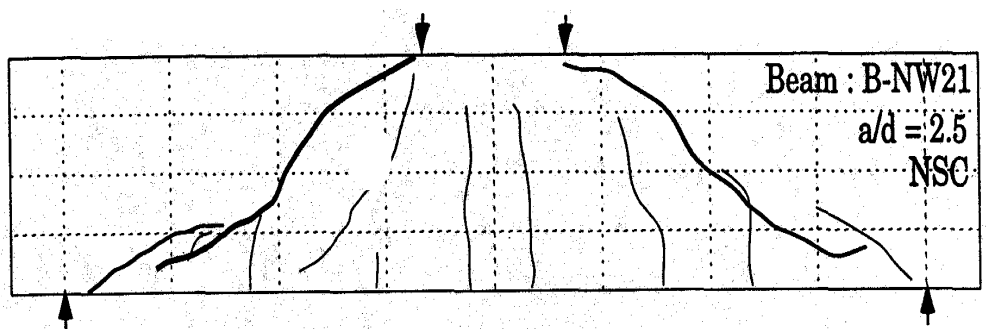

(d)

Figure 4. Final cracking pattern: (a) ANW21 numerical model; (b) ANW21 experiment; (c) BNW21 numerical model; (d) BNW21 experiment.
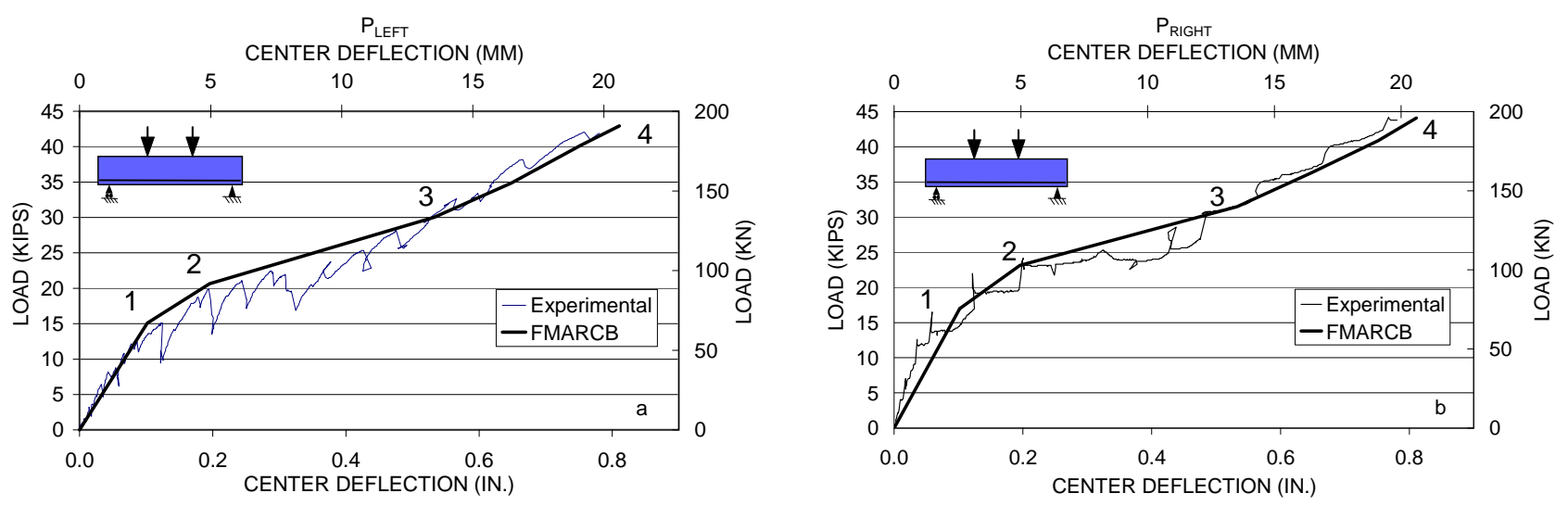

Figure 5. Left and right load displacement responses, respectively, for ANW21. 
$P_{\text {LEFT }}$

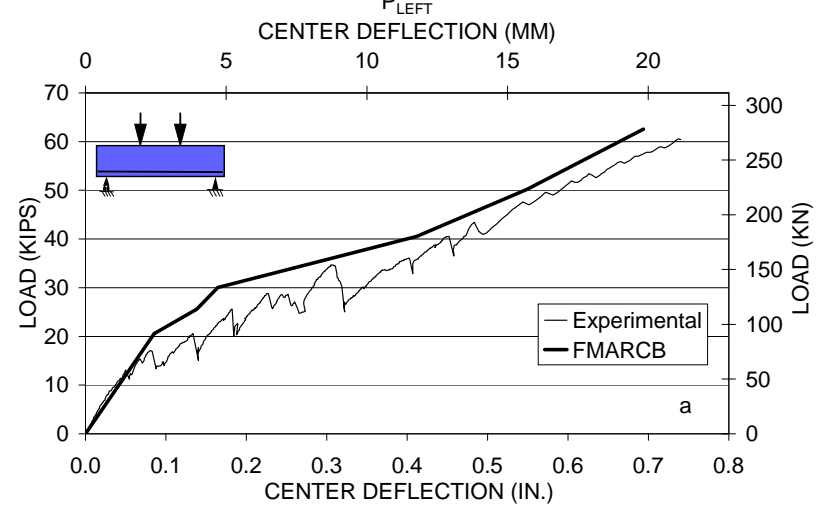

$\mathrm{P}_{\mathrm{RIGHT}}$ CENTER DEFLECTION (MM)

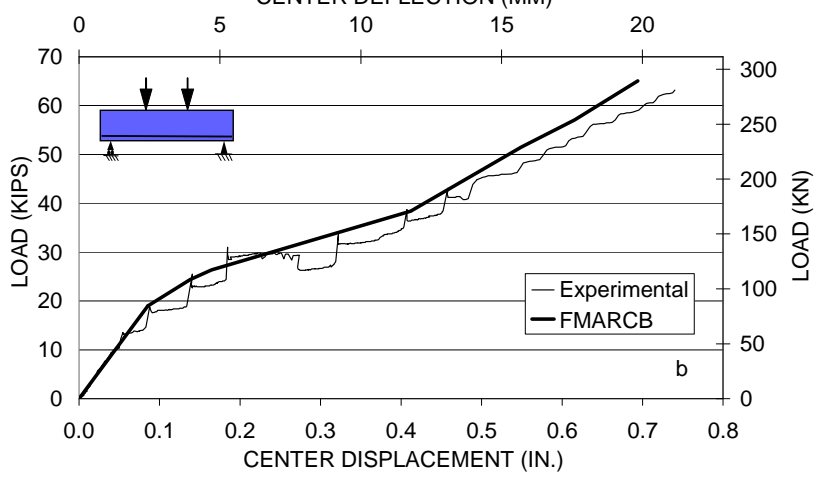

Figure 6. Left and right load displacement responses, respectively, for AHW22.

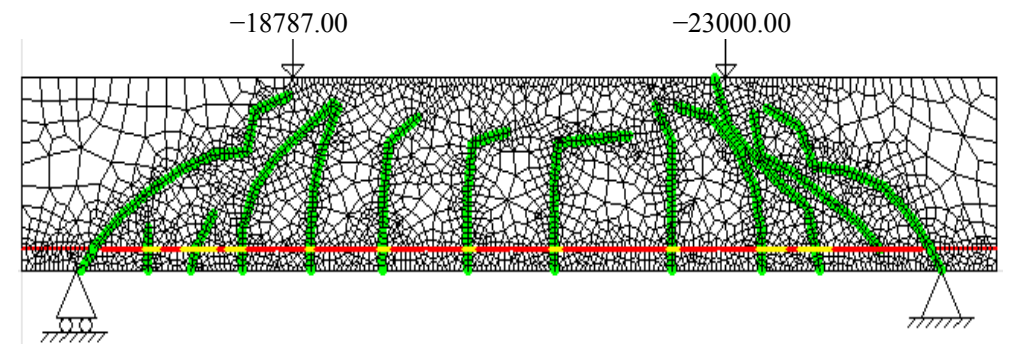

(a)

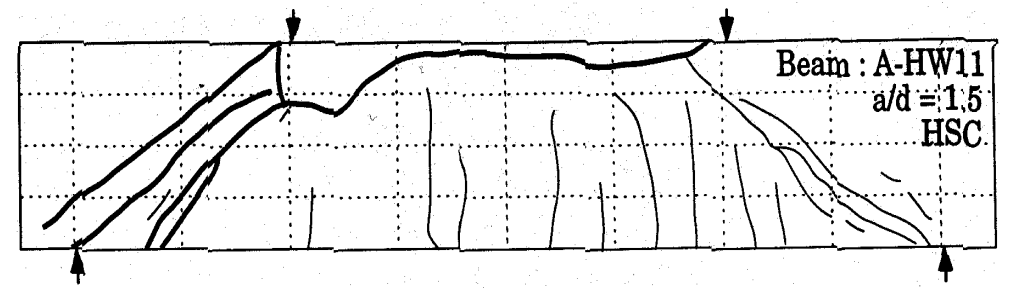

(b)

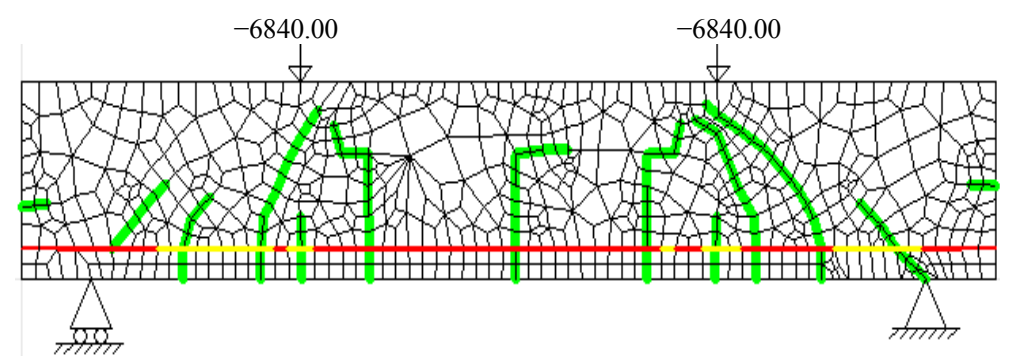

(c)

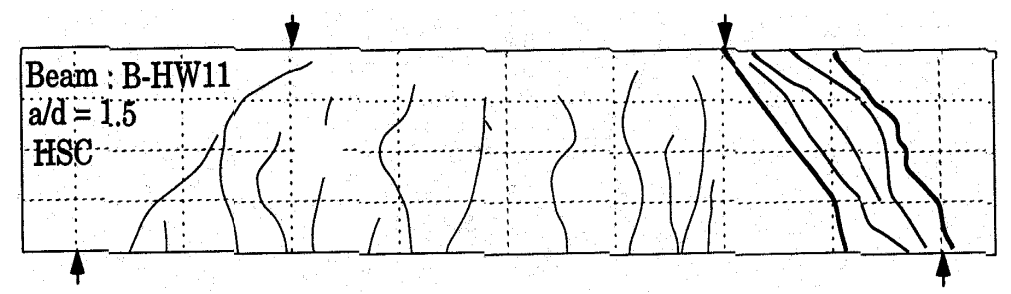

(d)

Figure 7. Final cracking pattern: (a) AHW11 numerical model; (b) AHW11 experiment; (c) BHW11 numerical model; (d) BHW11 experiment. 
combination of ultimate diagonal tension failure and shear compression failures resulted from the catastrophic growth of these diagonal cracks. Shear compression failure occurred when diagonal cracks penetrated the compression region and compressive strength was reached (Figure 7). Reinforcement yielding began prior to the ultimate failure (Figures 8 and 9, Point 1).

The load displacement responses for Size B are shown in Figures 10 and 11. For these beams, analyzed with an a/d ratio of 1.5 and 2.5 , a diagonal compression and a diagonal shear failure similar to the one discussed for the

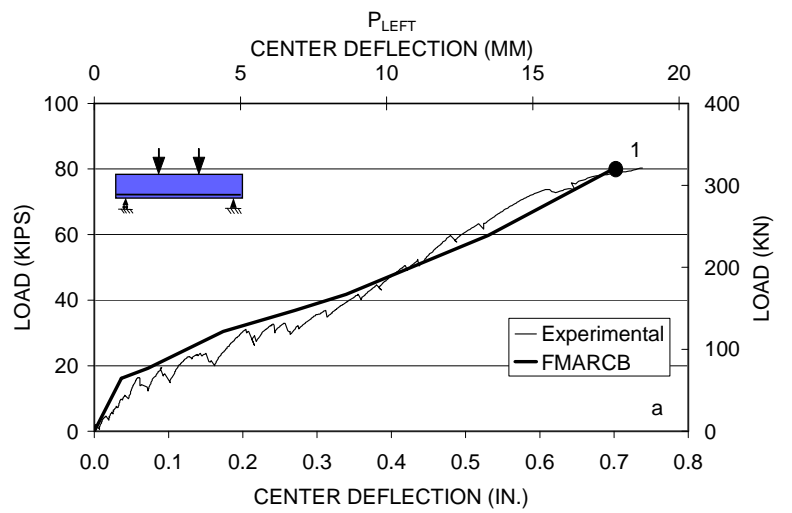

Size A beam were observed. However, a fewer number of cracks were observed prior to failure.

General observations on the crack patterns. Figures 4 and 7 include numerical and experimental cracking patterns of the two different beam sizes without stirrup reinforcement for NSC beams with an a/d ratio of 2.5 and HSC beams with an $a / d$ ratio of 1.5 . NSC beams with an $a / d$ ratio of 1.5 and HSC beams with an $a / d$ ratio of 2.5 were observed to have a somewhat similar cracking pattern in contrast to the beams with similar $a / d$ ratios.

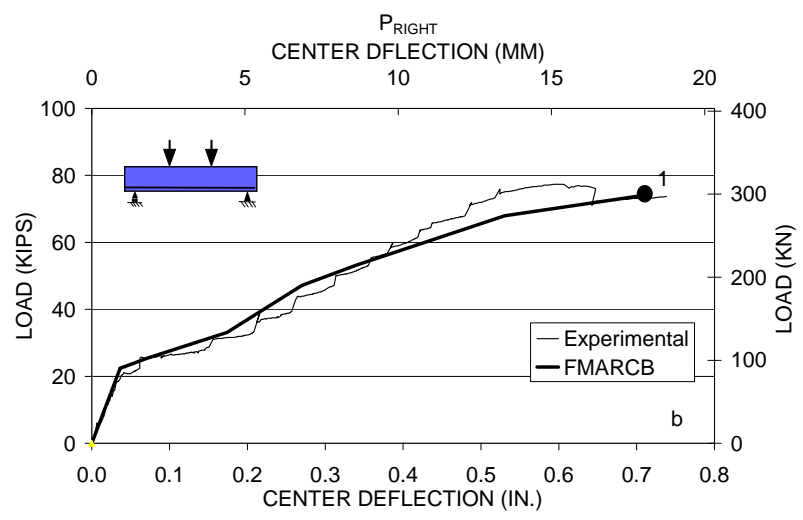

Figure 8. Left and right load displacement responses, respectively, for ANW11.
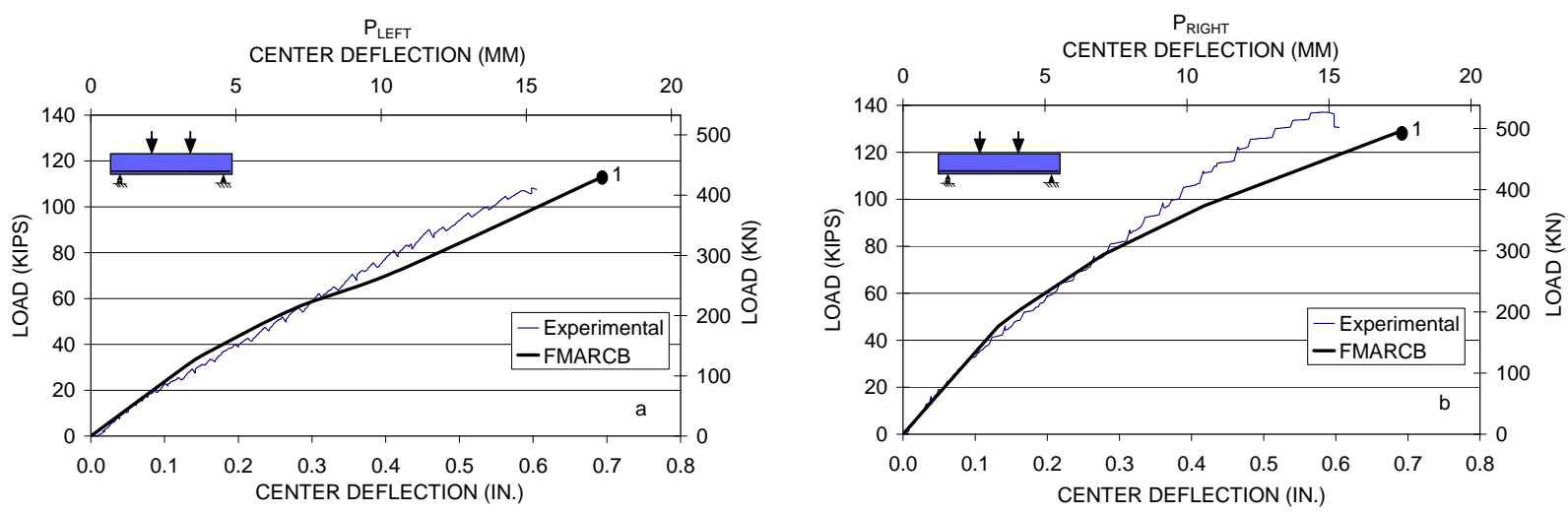

Figure 9. Left and right load displacement responses, respectively, for AHW11.
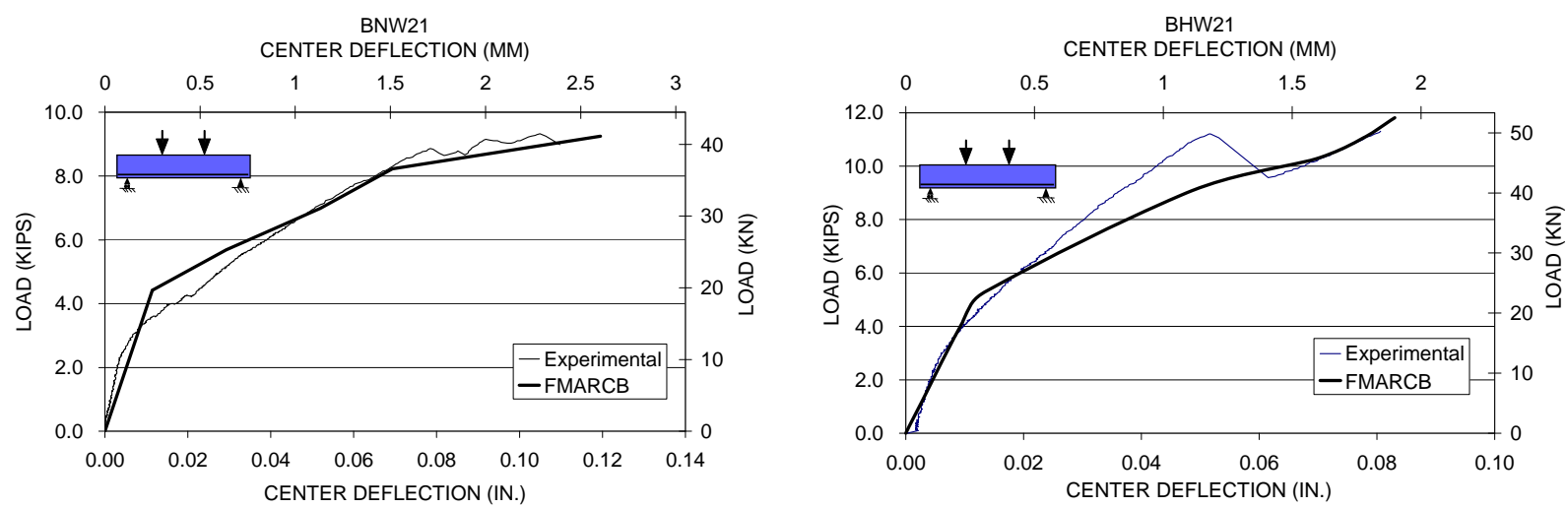

Figure 10. Load displacement responses for BNW21 and BHW21. 

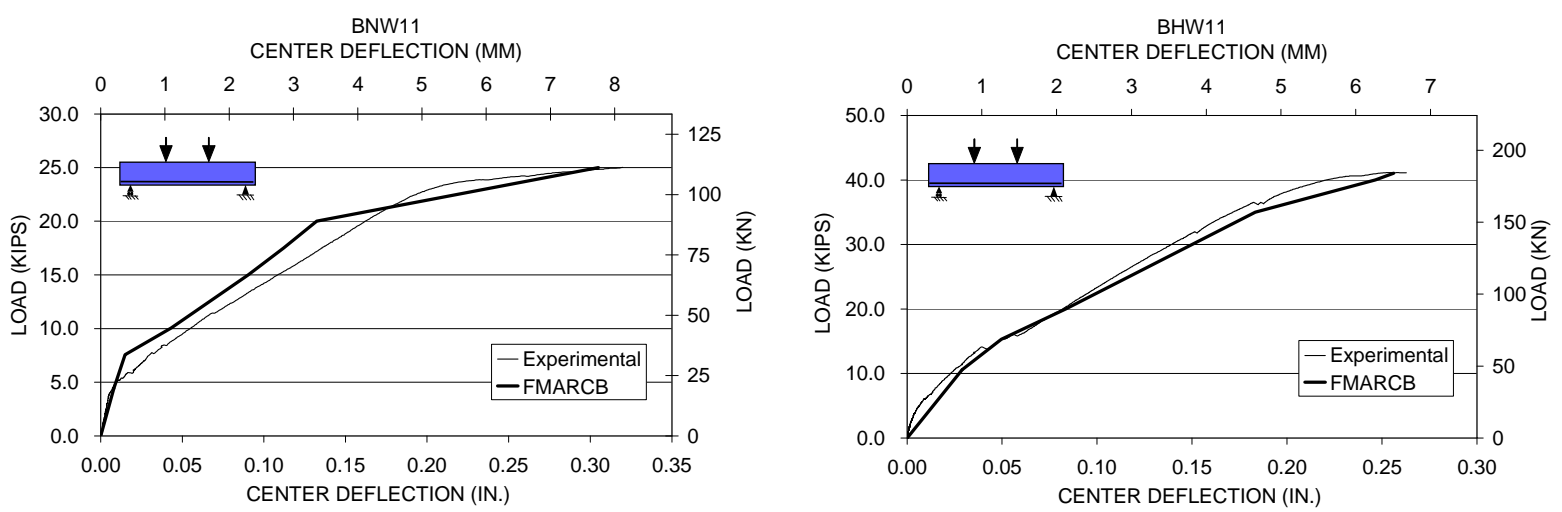

Figure 11. Load displacement responses for BNW11 and BHW11.

Figure 7 shows a unique type of failure; shear compression after yielding of longitudinal steel (AHW11). For the $a / d$ ratio used (1.5) and the material parameters chosen for HSC (Table 2), the shear capacity and flexural capacity are nearly comparable. The diagonal crack penetrated the compression region, and compressive strength was reached. Failure in NSC beams without lateral reinforcement was observed to be often accompanied by debonding of the longitudinal reinforcement (Figure 4). For both the NSC and HSC beams, general inclination of diagonal cracks was influenced by $a / d$ ratios used. For an $a / d$ ratio of 1.5 , main diagonal cracks appeared to span from the support to the load point in each shear span (Figure 7). For an a/d ratio of 2.5, the diagonal cracks were generally $z$-shaped, often connected with debonding of the longitudinal reinforcement (Figure 4). Debonding started when the first flexural crack crossed the longitudinal reinforcement and ended at catastrophic diagonal tension shear failure. The general crack and failure patterns obtained from the numerical analysis in each case correlated well with those obtained from the experiments.

Crack patterns and failure modes in the smaller size (Size B) of NSC and HSC beams without stirrup reinforcement for $a / d$ ratios of 1.5 and 2.5 are similar to those for Size A beams analyzed at the same $a / d$ ratios. Generally, the numerical model predicted fewer cracks, which is similar to experimental observations for smaller beams (Size B) [20].

Influence of specimen size. Brittle fractures [3,6,28] are responsible for size effects observed in concrete structures. Shear failures in reinforced concrete beams without shear reinforcement have been observed to be more sensitive to beam size. Since many factors such as material property, reinforcement content, and loading geometry affect brittleness of shear failure, it is expected that these parameters will likely influence the size effect as well. While the understanding of size effect in the failure of plain concrete is good, only limited conclusive data are available on how reinforcement affects size effect. It is generally believed that if the reinforcement remains elastic and bonded to concrete, size effect similar to that observed for plain concrete will also be observed for reinforced concrete; however, if reinforcement yields or slips, the size effect is expected to become milder or stronger, respectively. Also, the presence of lateral reinforcement is expected to make size effect insensitive. Even though voluminous data on shear failure of reinforced concrete beams are available in the literature, only a limited number of these investigations provide all the information needed for systematic fracture analysis. It is hoped that the data obtained from the numerical modeling in this investigation would be a modest beginning in providing additional answers to questions on size effect in failure of reinforced concrete.

Diagonal crack initiation has been reported to be less size dependent than ultimate failure in shear failure [29]. This observation is also valid based on the analysis completed for this investigation; however, the differences are less significant in magnitude. A closer examination of the numerical models and the experimental results showed that size effect at diagonal crack initiation was only marginally less size dependent than that at ultimate failure for very deep beams without stirrup reinforcement. A 42 percent reduction in strength at diagonal crack initiation for an increase in effective depth from 0.2 to $0.8 \mathrm{~m}$ ( 8 to 32 in.) compared to an approximately 47 percent drop in the ultimate capacity for a corresponding increase in specimen depth (strut and tie action in the post-diagonal cracking regime reported for these specimens). It should be noted that conclusions on the extent of size effect at ultimate capacity are strongly dependent on the failure mode.

Size effect is milder for an $a / d$ ratio of 1.5 than for one of 2.5 for both the NSC and HSC beams. Strength reduction caused by shear failure as a function of $a / d$ ratios can be treated as a geometry or structural-configuration-related brittleness. If brittleness and size effect are implicitly related as implied in fracture mechanics analysis, it is not surprising that an a/d ratio of 2.5 would exhibit a 
stronger size effect. Ultimate shear strength presents a marginally milder size effect than that observed for diagonal cracking. It should be pointed out that these observations are from failures where yielding of longitudinal steel preceded ultimate failure in shear, implying that shear capacity may be comparable to the flexural capacity. Ultimate shear strength for HSC also exhibits only a mild size effect in spite of the fact that most failures are shear failures that occur prior to yielding of the longitudinal steel. Size effect is not significantly different from that observed at diagonal crack initiation. This is somewhat similar to the deep beam test reported by [29]. Caution should be exercised in making generalizations regarding the influence of size effect on the ultimate capacity of reinforced concrete beams, particularly when comparing failure types that are not exactly identical.

Influence of concrete strength. The stress at flexural cracking, diagonal crack initiation, and ultimate capacity are all larger for the HSC beams than for NSC beams. It was expected that the size effect for HSC would be stronger than for the NSC beams. No conclusive observations could be made concerning size effect either in diagonal crack initiation or at ultimate capacity. The size effect with regard to diagonal crack initiation was observed to be comparable in the two concrete materials. The size effect at ultimate capacity even with the slightly different failure modes (for beams without stirrup reinforcement) was again comparable. One possible explanation for the lack of distinct difference in size effect between the two concrete materials is that even though the compressive strength ratio is 1.7 , the tensile strength ratio is approximately 1.3. Perhaps if the compressive strengths differed by a greater amount, one could have possibly seen stronger size effect for the HSC material.

\section{Numerical Solution with Shear Reinforcement}

Numerical analyses of the Size A beams with shear reinforcement were conducted. The spacing and shear rein-

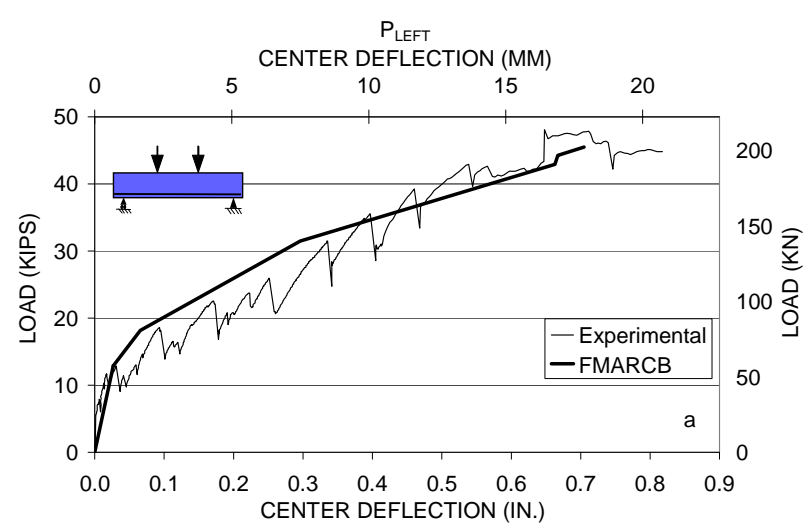

forcement content followed that was specified in [20]. Because of the confinement introduced by the shear reinforcement, a plane strain assumption was utilized in the analysis. Beam geometry is shown in Figure 1 and Table 1, and material properties for Size A beams are shown in Tables 2 and 3.

Typical load deflection response. Results from the numerical analysis of an NSC beam with lateral reinforcement (Beam ANS22) and a shear-span-to-depth ratio of 2.5 indicated a flexural failure after yielding of the longitudinal steel reinforcement. One of the factors of this ductile type of failure is the confinement pressure provided by the shear reinforcement, which reduces the initiation and growth of tension shear cracks. Furthermore, the confinement pressure provides additional bonding capacity, limiting the debonding of the tensile reinforcement. Load displacement curves for Size A beams with shear reinforcement are shown in Figures 12-15. The capacity of this beam increased by 10 percent compared with that of the beam without shear reinforcement; however, the main contribution was that the failure mode changed from a brittle to a ductile failure.

In the case of NSC and HSC beams with stirrup reinforcement analyzed at an $a / d$ ratio of 1.5 , flexure failure occurred after yielding of the tensile reinforcement prior to crushing of the concrete. Once again, the confinement pressure provided by shear reinforcement delayed the initiation and catastrophic propagation of the diagonal tension cracks in each shear span (Figures 14 and 15).

In general, numerical results show that the presence of confinement pressure equivalent to the shear reinforcement does not make a significant difference in the performance of the Size A beams until the initiation of the diagonal cracks. Furthermore, the amount of confinement pressure equivalent to the stirrup spacing will greatly alter the failure mode in reinforced concrete beams. The general load deflection curves obtained from the numerical analysis in each case are comparable with those obtained from the experiments.

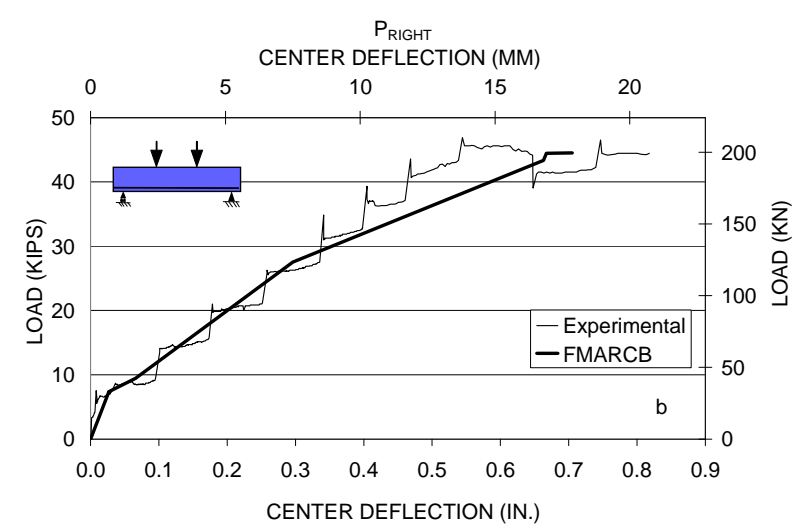

Figure 12. Left and right load displacement responses, respectively, for ANS22. 

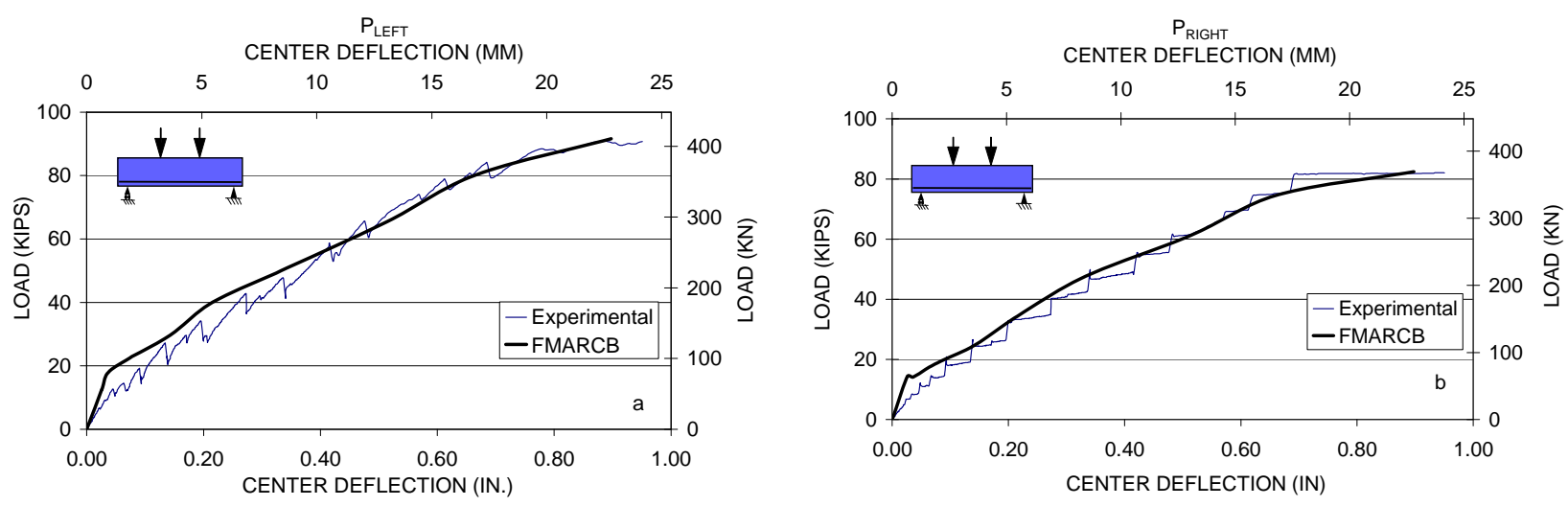

Figure 13. Left and right load displacement responses, respectively, for AHS22.
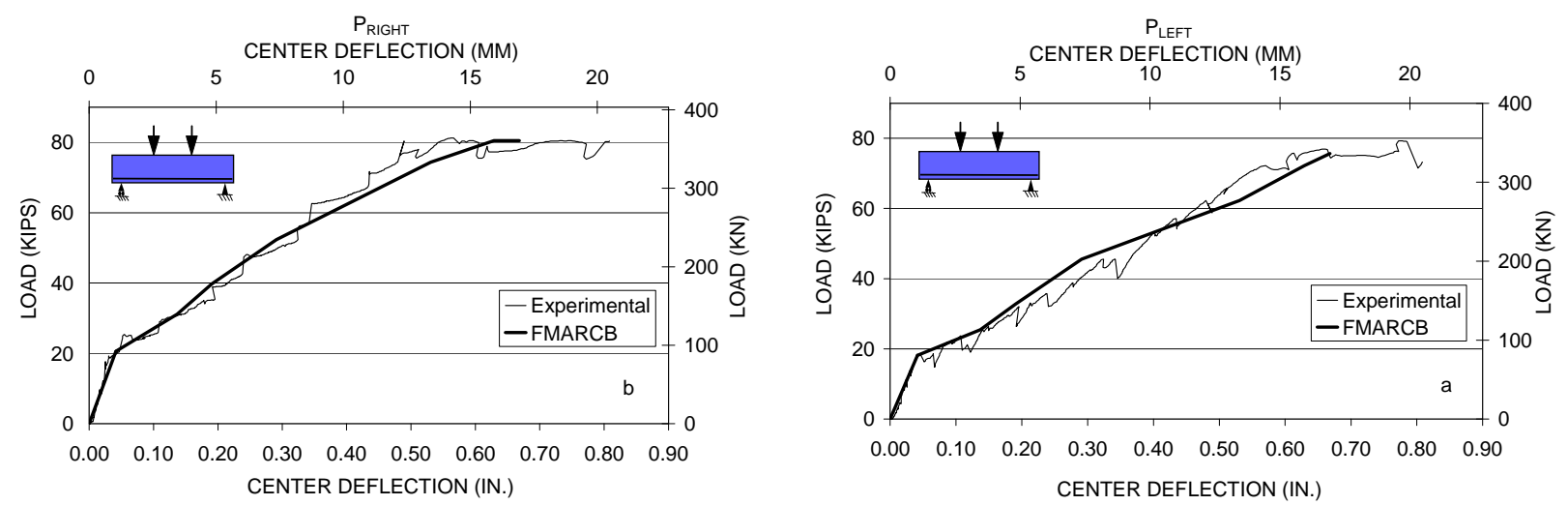

Figure 14. Left and right load displacement responses, respectively, for ANS11.
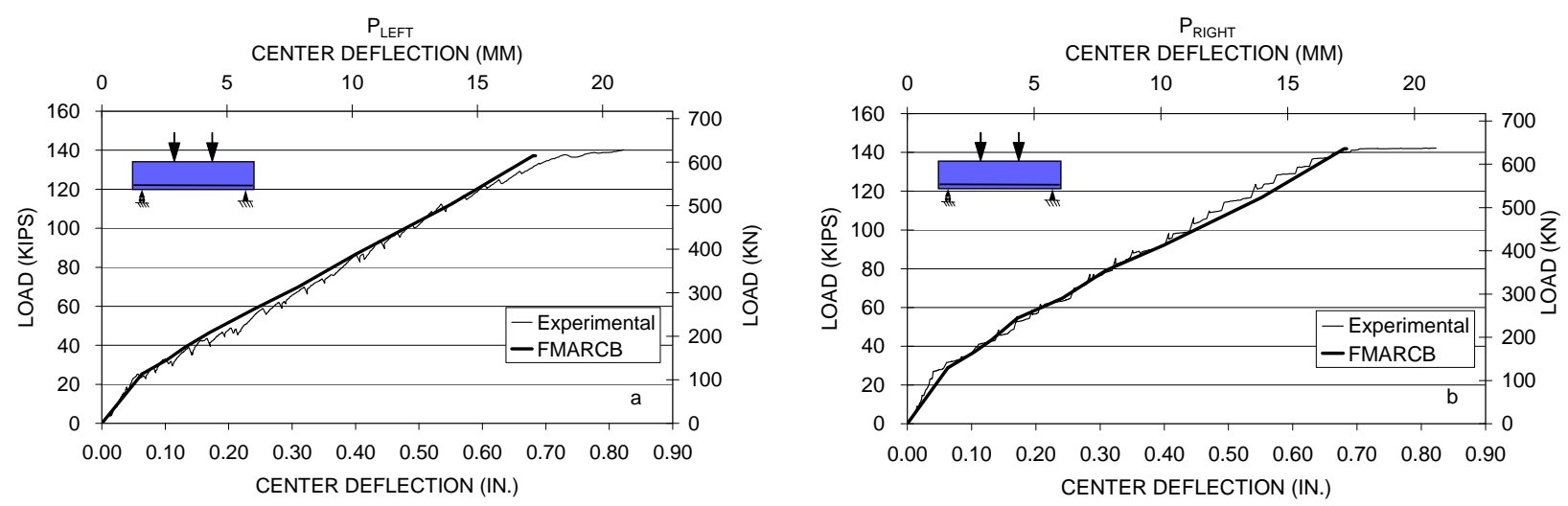

Figure 15. Left and right load displacement responses, respectively, for AHS11.

General observations on the crack patterns. Figure 16 includes numerical cracking patterns of Size A beams with stirrup reinforcement (confined pressure) for NSC and HSC beams with a/d ratios of 2.5 and 1.5 , respectively.

All Size A beams with shear reinforcement failed in flexure. For the a/d ratio of 2.5 and the material parameters chosen for NSC and HSC (Table 1), a reduction of the amount of debonding was observed in addition to a delay in the formation of the flexure shear cracks. For both the NSC and HSC beams, general inclination of diagonal cracks was influenced by $a / d$ ratios used; however, diagonal cracks did not propagate in an unstable manner, allowing the tensile reinforcement to yield prior to the crushing of the concrete. For an $a / d$ ratio of 1.5 , main diagonal cracks appeared to span from the support to the load point in each shear span (Figure 16). For an $a / d$ ratio of 2.5 , the diagonal cracks were generally $z$ shaped, often connected with reduced amount of debonding of the longitudinal reinforcement (Figure 16). Debonding started when the first flexural crack crossed the longitudinal reinforcement; however, the bonding capacity 


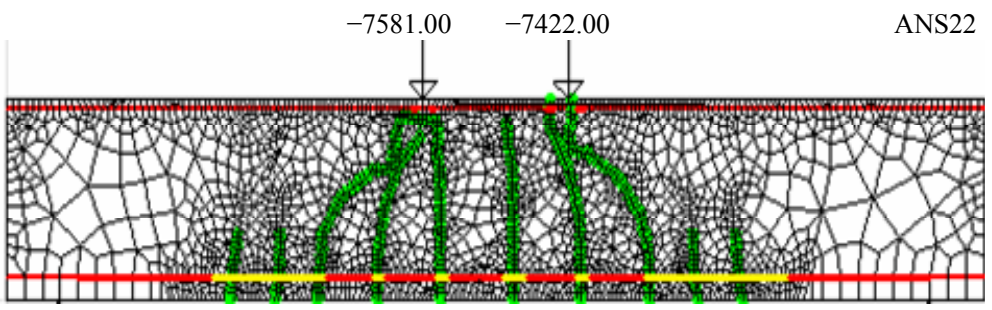

(a)

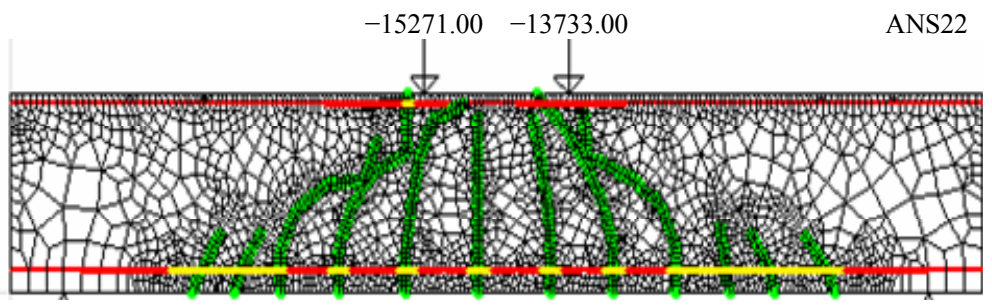

(b)

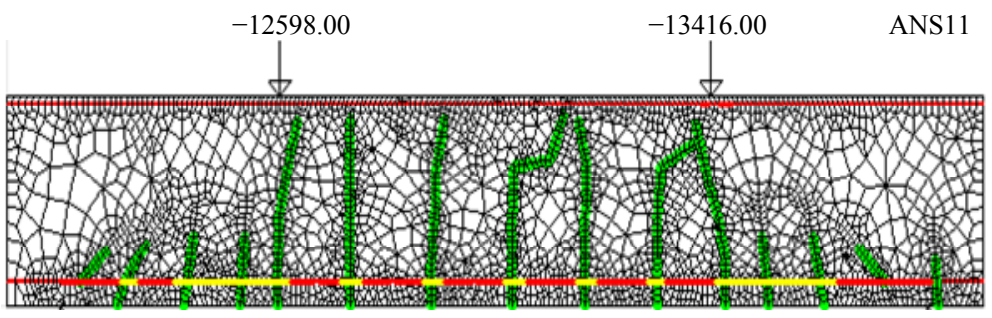

(c)

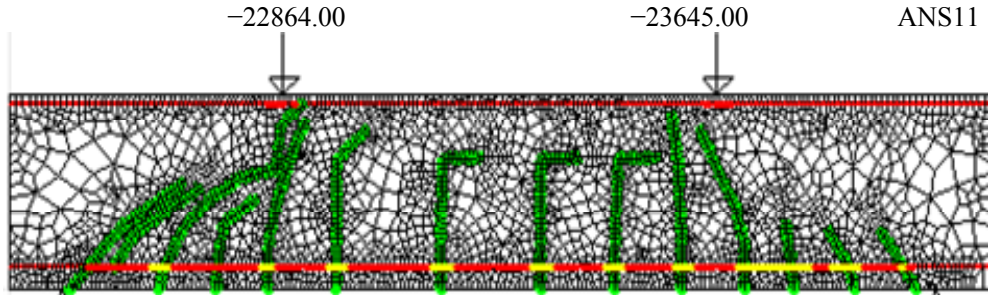

(d)

Figure 16. Final numerical cracking pattern for beams with shear reinforcement.

was larger because of the confinement pressure provided by the shear reinforcement, which allows a ductile type of failure.

\section{Conclusions}

Size effect in strength and deformation capacity. Brittle shear failure in NSC and HSC beams without stirrup reinforcement, exhibited effects of size on ultimate strength as well as corresponding deflections for effective beam depths of 0.2 and $0.8 \mathrm{~m}$ ( 8 and 32 in.). Stress at diagonal crack initiation was observed to be less size dependent. In this investigation, size effect at the ultimate shear capacity was only marginally more size-dependent than that observed for diagonal crack initiation. Size effect on the deflection capacity at diagonal crack initiation observed in the numerical analysis may be of practical relevance in design. Although direct comparison of size effect in the deflection value at the ultimate capacity was not made because of the differences in failure mechanisms, size effect similar to that at diagonal crack initiation was observed at this loading.

Shear-span-to-depth ratio and geometry-related brittleness. For the two shear-span-to-depth ratios investigated ( $a / d$ of 1.5 and 2.5), the failure in beams without stirrup reinforcement was due predominantly to diagonal tension and shear compression. Reduction in shear capacity compared to the flexural capacity in all cases investigated was more severe for the $a / d$ ratio of 2.5 . This is in line with Kani's [30] shear valley concept. Distinct changes in crack patterns and resultant mode of failure also accompanied changes in the $a / d$ ratio. Size effect was greater at an a/d ratio of 2.5. This observation can be 
treated as geometry-related brittleness in analytical models.

Concrete compressive strength. The shear strength of HSC beams (compressive strength of $70 \mathrm{MPa}(10,000$ psi)) was markedly higher than that of NSC beams (compressive strength $43 \mathrm{MPa}$ (6250 psi)) at diagonal crack initiation and at the ultimate capacity. Even while the HSC was more brittle than the NSC, no noticeable differences in the size effect on failure loads were observed.

Nonlinear fracture mechanics-based model. The nonlinear fracture mechanics-based numerical model described herein has unique features including automated crack initiation and propagation, automated remeshing, and solution of several nonlinear phenomena (concrete softening in tension and compression, bond slip, and yielding of reinforcement).

The numerical model developed to study the shear behavior of reinforced concrete deep beams has been validated with eight beams of two different sizes with different material properties and loading geometries. The model successfully predicted the ultimate capacity of the beams described herein. The model shows good correlation between the predicted cracking pattern and the experimental cracking pattern. It also predicted the load displacement response successfully. Bond-slip characteristics exert significant influence on load deflection characteristics of the reinforced concrete deep beams and should be implicitly incorporated into any numerical fracture model for the flexural behavior of reinforced concrete beams. The model also shows no need to use the shear capacity for the tension softening.

\section{Acknowledgements}

The development of the numerical model was funded by the Computer-Aided Structural Engineering (CASE) Project of the US Army Corps of Engineers and the Information Technology Laboratory (ITL) of the US Army Engineer Research and Development Center (ERDC). Mr. Amos Chase, Scientific Applications International Corporation, and Mr. Barry White, ITL, made significant contributions to writing the computer code. Permission was granted by the Chief of Engineers to publish this information.

\section{REFERENCES}

[1] ACI Committee 318, "Building Code Requirements for Structural Concrete and Commentary (ACI 318-95 and 318R-95)," American Concrete Institute, Detroit, 2008.

[2] A. Hillerborg, M. Modeer and P. E. Peterson, "Analysis of Crack Formation and Crack Growth in Concrete by Means of Fracture Mechanics and Finite Element," $\mathrm{Ce}$ ment and Concrete Research, Vol. 6, No. 6, 1976, pp. 773-782.

http://dx.doi.org/10.1016/0008-8846(76)90007-7
[3] ACI Committee 446, "Fracture Mechanics of Concrete: Concepts, Models and Determination of Material Properties," ACI 446.1R-91, Reported by ACI Committee 446, Detroit, 1991.

[4] American Concrete Institute (ACI), "Finite Element Analysis of Fracture in Concrete Structures: State-of-theArt," ACI 446.3R-97, Reported by ACI Committee 446, Detroit, 1997.

[5] T. L. Anderson, "Fracture Mechanics, Fundamentals and Applications," 2nd Edition, CRC Press, Washington DC, 1994.

[6] Z. P. Bažant and J. Planas, "Fracture and Size Effects in Concrete and Other Quasibrittle Materials," CRC Press, Washington DC, 1997.

[7] ACI Committee 446, "Fracture Mechanics Applications to Concrete Structures and Implications with Regard to the Code," American Concrete Institute, Detroit, 1992.

[8] Y. R. Rashid. "Analysis of Pre-Stressed Concrete Pressure Vessels," Nuclear Engineering and Design, Vol. 7, No. 4, 1968, pp. 334-355. http://dx.doi.org/10.1016/0029-5493(68)90066-6

[9] Z. P. Bažant, "Comment on Hillerborg's Comparison of Size Effect Law with Fictitious Crack Model," Dei Poli Anniversary Volume, Politecnico di Milano, 1985, pp. 335-338.

[10] ASCE Committee 447, "State of the Art Report on Finite Element Analysis of Reinforced Concrete," American Society of Civil Engineers, New York, 1982, p. 545.

[11] ASCE Committee 447, "State of the Art Report on Finite Element Analysis of Reinforced Concrete," American Society of Civil Engineers, New York, 1994, p. 545.

[12] Comite Euro-International du Beton (CEB) and the Federation Internationale de la Precontrainte (FIP), "CEBFIP Model Code 1990,” CEB Bulletin D'Information No. 213/214, Lausanne, 1993.

[13] D. Coronelli and G. Mulas, "Modeling of Shear Behavior in Reinforced Concrete Beams," ACI Structural Journal, Vol. 103, No. 3, 2006, pp. 372-382.

[14] A. Hillerborg, "Analysis of One Single Crack," In: F. H. Wittmann, Ed., Fracture Mechanics on Concrete, Development in Civil Engineering, Elsevier Science Publishers, Amsterdam, 1983, pp. 223-249.

[15] Z. P. Bažant and V. S. Gopalaratnam, "Fracture Mechanics of Concrete: An Apercu of Basic Concepts and Models," Proceedings of the First International Conference on Fracture Mechanics of Concrete Structures, Breckenridge, Colorado, 1-5 June 1992, pp. 145-154.

[16] S. P. Shah, A. Fafitis and R. Arnold, "Cyclic Loading of Spirally Reinforced Concrete." Journal of the Structural Division, Vol. 109, No. ST7, 1983, pp. 1695-1710. http://dx.doi.org/10.1061/(ASCE)0733-9445(1983)109:7( 1695)

[17] S. Hayashi and S. Kokusho, "Bond Behavior in the Neighborhood of the Crack," Finite Element Analysis of Reinforced Concrete Structures; Proceedings of the Seminar Sponsored by the Japan Society for the Promotion of Science and the US National Science Foundation, Tokyo, 21-24 May 1985, pp. 364-373. 
[18] J. Ruppert, “A Delaunay Refinement Algorithm for Quality 2-Dimensional Mesh Generation," Journal of Algorithms, Vol. 18, No. 3, 1995, pp. 548-585. http://dx.doi.org/10.1006/jagm.1995.1021

[19] S. J. Owen, M. L. Staten, S. A. Canann and S. Saigal. "QMorph: An Indirect Approach to Advancing Front Quad Meshing," International Journal for Numerical Methods in Engineering, Vol. 9, No. 44, 1999, pp. 1317-1340. http://dx.doi.org/10.1002/(SICI)1097-0207(19990330)44: 9<1317::AID-NME532>3.0.CO;2-N

[20] M. G. Khorasgany, "Size Effect in Shear Failure of Normal and High Strength RC Beams," Ph.D. Dissertation, University of Missouri, Columbia, 1994.

[21] M. G. Khorasgany and V. S. Gopalaratnam, "Shear Strength of Concrete-Size and Other Influences," Size Effect in Concrete Structures: Proceedings of the Japan Concrete Institute International Workshop, Sendai, 31 October-2 November 1993, pp. 67-78.

[22] V. S. Gopalaratman and S. P. Shah, "Softening Response of Plain Concrete in Direct Tension," ACI Journal, Vol. 82, No. 3, 1985, pp. 310-323.

[23] G. A. Riveros, V. S. Gopalaratnam and A. Chase, “User's Guide: Fracture Mechanics Analysis of Reinforced Concrete Beams (FMARCB)," ERDC/ITL TR-08-1, US Army, Engineer Research and Development Center, Vicksburg, 2008.

[24] P. E. Petterson, "Crack Growth and Development of Fracture Zone in Plane Concrete and Similar Materials,"

\section{Notation}

The following symbols are used in this paper:

$A=$ constant that was statistically evaluated from experimental data of unconfined and confined concrete subjected to monotonically increasing loading

$A_{s}=$ tension steel reinforcement area

$A_{s}^{\prime}=$ compression steel reinforcement area

$A_{v}=$ area of the lateral (shear) reinforcement

$a / d=$ shear-span-to-depth ratio

$b=$ width of beam

$d=$ effective depth

$d_{c}=$ concrete core diameter

$d_{s}=$ bar diameter

$E=$ modulus of elasticity

$E_{c}=$ secant modulus of elasticity

$E_{s}=$ module of elasticity of the reinforcement

$f=$ concrete stress at a predefined strain

$f_{c}^{\prime}=$ compressive strength

$f_{r}=$ confinement pressure

$f_{t}=$ tensile strength

$f_{y}=$ yield strength of the reinforcement

$f_{0}=$ peak stress
Report No. TVBM-1006, Division of Building Materials, Lund Institute of Technology, Lund, 1981.

[25] W. H. Gestle and M. Xie, "FEM Modeling of Fictitious Crack Propagation in Concrete," Journal of Engineering Mechanics, Vol. 118, No. 2, 1992, pp. 416-434. http://dx.doi.org/10.1061/(ASCE)0733-9399(1992)118:2( $\underline{416)}$

[26] M. Keuser and G. Mehlborn, "Finite Element Models for Bond Problems," Journal of Structural Engineering, Vol. 113, No. 10, 1987, pp. 2160-2173.

http://dx.doi.org/10.1061/(ASCE)0733-9445(1987)113:10 $(2160)$

[27] A. C. Scordelis and D. Ngo, "Finite Element Analysis of Reinforced Concrete Beams," ACI Journal, Vol. 64, No. 3, 1967, pp. 152-163.

[28] A. Carpinteri, "Size Effect in Fracture Toughness Testing: A Dimensional Analysis Approach," Proceedings of an International Conference on Analytical and Experimental Fracture Mechanics, Rome, 23-27 June 1980, pp. 785797.

[29] J. C. Walreven. "Scale Effects in Beams without Reinforced Webs, Loaded in Shear," Progress in Concrete Research, Annual Report, Vol. 1, No. 99, 1990, pp. 101112.

[30] G. N. J. Kani, "How Safe Are Our Large Reinforced Concrete Beams?" Proceedings of ACI Structural Journal, Vol. 64, No. 3, 1967, pp. 128-141.

$G_{f}=$ fracture energy

$H=$ beam height

$k=$ constant that was statistically evaluated from experimental data of unconfined and confined concrete subjected to monotonically increasing loading

$L=$ beam length

$S=$ distance between beam supports

$s=$ spacing between stirrups on beam geometry definition

$=$ slip on bond-slip curve definition

$t=$ thickness

$u_{c}, u_{s}=$ displacement of concrete and steel, respectively

$w_{c}=$ critical crack opening displacement value

$x=$ distance from the crack-rebar intersection center line to the desirable location

$\alpha=$ reduction factor

$\varepsilon=$ predefined concrete strain

$\varepsilon_{0}=$ peak strain

$v=$ Poisson's ratio

$\tau_{\max }, \tau_{\min }=$ maximum and minimum bonding strengths, respectively 